ANATOL RAPOPORT

\title{
A view of the intellectual legacy of Karl Marx*
}

\begin{abstract}
A dispassionate discussion of Marxism as an intellectual heritage has been persistently difficult because of the strong philosophical commitments and political polarization of its adherents and its opponents. However, with the passage of time and the gaining of perspective, an evaluation becomes easier. It appears, in fact, that the legacy of Marxism derives great value precisely from the intensity of the controversies that have ranged around it.

It has been fashionable for a while in the United States (a legacy of logical positivism) to declare all purely philosophical disputes to be " meaningless ". They can readily be made to appear so by rigid demands for operational definitions, for specifications of verification procedures, and so on. There are, however, many criteria of meaningfulness, and one of importance is the extent to which a controversy reflects fundamental clashing commitments. It may well happen that the issues of the controversy are " meaningless" in the sense of not being rooted in empirical criteria of meaning, but the actual results of the controversy may nevertheless be of vital significance to intellectual history. These results make the controversy meaningful in retrospect.

An instructive example of this effect of philosophical dispute can be seen in the running controversy between the " mechanists " and the "vitalists " in biology, much of which was conducted on the metaphysical rather than on the scientific plane. The mechanists were those who

- This article was presented as a paper for the Symposium on the influence of Karl Marx on contemporary scientific thought, Paris, May 8-10, 1968, organized under the auspices of Unesco by the International Social Science Council and the International Council for Philosophy and Humanistic Studies.
\end{abstract}


maintained that life processes should be explained entirely on the basis of known physical and chemical laws. The vitalists insisted that a special " life force ", or " vital principle ", guided the living processes. The question, as it is put, cannot be settled on scientific grounds. It is a philosophical question, to which one gives an answer in accordance with one's ideational commitments. Clearly, no matter how many of the specific life processes (e.g., physiological events) the mechanists could show to be derivable from the physico-chemical matrix of the events in question, the vitalists were not thereby obligated to abandon their view, since these events could constitute only a minute fraction of the enormously complex processes which we call life.

Fortunately for the development of biology, not all vitalists confined their arguments to the philosophical level. Some cited specific phenomena which, they maintained, implied the operation of vital forces. As these phenomena were shown to be derivable from known physical laws, the arguments of the vitalists were refuted. In a way, the maturation of the biological sciences coincides with the abandonment by the vitalists of a sequence of positions. With the synthesis of urea (1828), for example, it became clear that no special " vital force " was involved in the production of the so-called organic compounds. The application of the principles of thermodynamics to biochemical reactions failed to reveal any unaccounted for sources of energy in living beings. The discovery of the conditioned response laid the foundations for a " materialistic " theory of modification of behavior, hence essentially of learning. And now principles of cybernetics are providing the foundation of a theory in which purposeful and " intelligent" behavior can be deduced as a consequence of an organized arrangement of material units.

Can we say, then, that vitalism has been " defeated " or, in view of its continued retreat, is doomed to final defeat as an outlook? An antivitalist might say so, if what he values most is a sense of triumph over philosophical opponents. I too am an anti-vitalist; but I do not think that vitalism has been " defeated ". I would rather say that responsible vitalism has served the purpose of a catalyst in the maturation of biology; has served as a challenge, if you will. In their retreat " to previously prepared positions" the vitalists invited an attack on those positions and so provided grist for the intellectual mill.

What is more significant, however, is that as vitalism retreated the anti-vitalist philosophy of biology radically changed. The anti-vitalist can no longer call himself a mechanist in the original sense of the word. Life processes, it has turned out, cannot be explained by purely mechanical models, such as the clockwork analogies of Descartes. The " physical explanation " of today is widely different from the physical explanations of the seventeenth, the eighteenth, and the nineteenth centuries. In retrospect we see the classical process at work : the thesis of mechanism clashing with the anti-thesis of vitalism, resulting in a sequence of syntheses in which neither of the positions appears in its original guise. 
This is the sort of process that might manifest itself in the development of social science if Marxist and anti-Marxist positions could interact in a creative way, each challenging the other on specific issues, compelling the antagonists to descend from the level of philosophical dispute to the examination of concrete events. It may still come to pass. If so, what emerges may consign all the tenaciously held positions to the museum of intellectual history; not to the " dust bin " or the " graveyard ", as those would have it who see every clash of philosophies as a battle, but to the museum where they will remain enshrined as monuments to the search for truth.

It is the fate of every scientific theory to be eventually proven to be "wrong ". To deny this is to deny the dialectics of science. To refute a theory, however, is not to declare it worthless. Refuted theories have not lived in vain any more than mortal men have lived in vain. A significant theory, even though refuted, lives on in its successors. I think it is worthwhile to keep this in mind when the content of Marx's socioeconomic theories is challenged or defended on scientific grounds.

A central idea in the Marxist approach to the theory of social change is that scientific inquiry need not be confined to the non-human universe (physical and biological science) but can be extended also to man, in particular, to social man and and his works. "Man " and "social man " are synonymous terms in the Marxist lexicon. Indeed, from the point of view of the Marxist outlook, the social aspects of man's existence are primary to the emergence of the individual psyche. There is good evidence for this view. If we can draw conclusions from observations on social primates, we can easily infer that the humanoid became social before he became man. Thus the point of departure in Marxist social philosophy is the social complex from which man's individual consciousness has emerged and by which it is molded. This view is diametrically opposed to the 18th century view of the origin of society as a conglomeration of initially (and ideally) autonomous psychological units.

The 18th century view is worth examining more closely because it still prevails in countries with the strongest culturally individualist bias against Marxist social philosophy, for example, in the United States. Specifically, we read in the Declaration of Independence, for instance : "That to secure these rights (life, liberty, and the pursuit of happiness) governments are instituted among men ".

The statement can be understood in two ways : first, as an assertion about the origin of organized social life; second, as a prescription of what governments ought to be. The second interpretation, being a normative one, is subject to dispute but hardly to empirical verification. The first 
interpretation, however, is descriptive, not normative, and hence can be evaluated in the light of evidence. As a statement of fact, it is manifestly false. Governments were not " instituted ". Organized social life evolved in a continuum, first in the biological context among our prehuman progenitors by the process of natural selection (like all other patterns of living existence), later in human societies by some other (non-biological) evolutionary principle. To be sure, on occasions people established formal covenants with each other, but they could do so only because they already had experience in organized social life; and this experience reaches far into our pre-human past.

The Marxist model of society charts the course of social evolution and names the principles which govern it. A methodological question is immediately raised thereby. To what extent can man and his works be understood in the light of the idea that society as an entity sui generis has evolved as a consequence of certain "forces " acting on it from the outside or generated from within it? The question ought to be the central one in evaluating Marxist philosophy of social science.

There is a current in modern philosophy of science called general systems theory. Its ideational source stems from biology and from some philosophical ideas formulated rather vaguely by, among others, Alfred North Whitehead. These ideas were a reaction, or a dialectical antithesis, if you will, to the predominant direction of the scientific method, namely the analytical approach. The analytic point of view seeks to understand the whole by first gaining an understanding of the parts. The system point of view, on the other hand, seeks to understand the parts by gaining an insight into the nature of the whole (the system) of which the parts are constituents.

As in many other confrontations of this sort, arguments about the relative value of the two approaches are largely a waste of time. Each has its place, and both are enhanced in value if they can be made to complement each other. The "reaction " against the analytic approach must be seen as a reaction against its hegemony, not against its applications where it is appropriate. When a methodology or an epistemology becomes enshrined as the scientific method, it becomes stifling, for it chokes off the opportunities for conceptual re-organization. Such re-organizations are indispensable for the preservation of science as a creative, dynamic method of cognition.

In fact, the analytic approach itself once played the role of an innovating re-organization of concepts. Pre-cartesian geometry, being " synthetic ", used configurations (polygons, circles, solids) as the units of analysis, deriving the relations of their parts from the properties of the wholes. Cartesian geometry, being analytic, introduced a revolutionary organization of concepts. The elements (coordinates of points) became the units of analysis. From the functional relations among these coordinates (equations of lines, surfaces, etc.) the properties of configurations were deduced, to the vast enrichment of geometry and eventually of other 
branches of mathematics. Next, pre-galilean physics was " organismic", seeking to understand the motions of bodies on the basis of their "natures", " affinities ", and teleological "strivings". In fact, pre-galilean physics had a strong biological flavor. Galilean physics, on the other hand, was analytic. It laid the foundations for the science of motion (kinematics) by calling attention to the elements of motion. Upon these foundations the mathematical bases of modern mechanics were laid. The differential equation, the prototype description of a mechanical process, is actually a representation of such a process analyzed into its infinitesimal constituent parts. Such have been the achievements of the analytic approach when it was new, revolutionary, as it were.

Let us look at what happened after the analytic approach became established as " the " scientific procedure. Classical economics was an attempt to build up a picture of the economic process from postulated inter-relations between primitive economic units (individual " producers ", "traders" and "consumers"). Behaviorist psychology sought to understand the behavior of an organism through the study of elementary stimulusresponse links. The empirical-pragmatic school of jurisprudence conceived the emergence of law as the sum-total of " precedents ". Rigorization of linguistics revealed the "structural units " of languages, a formidable achievement; but for a long time the structural linguists confined themselves to attempts to duplicate chemistry, as if the phonemes, morphemes, etc., were so many atoms and molecules whose "laws of combination " determined the properties of languages in the same way as the laws of combination of atoms and molecules determine the properties of matter. Even in anthropology some schools of thought arose in which the culture complexes were depicted in terms of catalogues of artifacts, customs, etc.

Granted that in many cases the extension of the analytic approach to areas far beyond the physical sciences led to respectable achievements, nonetheless the limitations of the approach soon became apparent. The "laws of supply and demand " could not account for some of the most salient features of modern economies ; stimulus-response psychology did not penetrate into the basic nature of recognition, insight, conceptualization, preference, not to speak of the deeper aspects of personality; linguists soon found out that by excluding meaning from linguistics they sterilized their science in both senses of the word.

The resurgence of a holistic, or organismic, point of view in modern guise centers around the concept of system, a complex of inter-related and inter-dependent parts. There is no need to deny that the properties of the system are in principle deducible from the properties of the parts and their inter-relations, and that therefore the analytic approach can be in principle used in the service of understanding organic wholes in terms of their parts. The question is not whether the analytic method is epistemologically sound, but rather concerns the limits of its applicability.

For example, it has been shown in statistical mechanics that the gross principles of thermodynamics, that is, holistic properties of certain physical 
systems, can be derived from the laws of mechanics and probability, applied to the particles that compose the system. However, once the thermodynamic laws are established, they can themselves be made points of departure in the construction of macroscopic physical theories, into which the microscopic concepts of particle mechanics do not enter.

Similary, certain sectors of psychology dealing with gestalt recognition, concept formation, etc., can be developed without reference to the neural events which underlie them. It is philosophically gratifying to assume that patterns of neural events in their totality determine the psychological states of the organism, that is, the gross properties of the " psychic system " (or the " mind ", to use a somewhat discredited term). It is even more gratifying to find links here and there between the " material " microcosm and the " ideational " macrocosm. But there is little methodological justification for refraining from pursuing the development of psychological macro-theories, pending the establishment in all respects of a continuum between neurophysiology and mental states. Similarly, it is not necessary to build linguistics from the phoneme up before developing a theory of language as a system in its own right with its own evolutionary laws.

In short, the system-theoretic approach permits the singling out for study of any system of interest, with the view of establishing its system properties, holding in abeyance the question of how these properties emerge from the laws governing the elements of the system and their interactions. The latter question should, of course, be examined. However, the point of the matter is that the examination may be more enlightening after the gross system properties have been understood.

To return to our example of thermodynamics, it will be recalled that the gross thermodynamic principles were discovered before the connections between them and molecular kinetics were established. In fact, it was the former discoveries (e.g., the role of entropy in thermodynamic systems) which instigated the investigations of statistical mechanics. Until thermodynamic principles came into the center of interest in physics and chemistry, there was no particular motivation for pursuing the implications of the kinetic theory of matter.

Marx's macro-sociology is an example par excellence of the system approach to social science. Singling out, what to his way of thinking, was the most important characteristic of human society, namely the division of labor, he proceded to deduce the evolution of the structure of social systems following the " impetus " of the institution of the division of labor. Implicit in Marx's evolutionary sociology is the idea that it is the internal dynamics of a system which propels it, as it were, along the path of development. 
THE BEING-CONSCIOUSNESS DICHOTOMY, A ND REDUCTIONISM

A philosophical tenet of Marxism is that " being is primary, consciousness secondary " - a subject of endless and, in my opinion, largely pointless disputes. Acclimatized as I am to the Anglo-Saxon empiricopragmatic atmosphere, I find it difficult to breathe the rarefied air of these disputes. Nevertheless, I think I see the connection between this tenet and the system-oriented approach to social science. The systemic view says that large human aggregates can be viewed as systems, each characterized by a structure; that is, a network of relations among its elements, including patterns of interaction among them. The " primacy of being over consciousness " can be interpreted in a methodological context instead of a metaphysical one. As a methodological prescription, the tenet says that the way people see and interpret their world (consciousness) can be better understood on the basis of some knowledge of the system of which they are a part (being) than the behavior of the system can be understood from the way the constituents seem to perceive the world (consciousness).

In Marxist writings, couched largely in 19th century philosophical terminology, the presumed laws governing the macro-social systems are declared to be manifestations of " objective reality ", while ideologies, world views, ethical imperatives, etc., are assumed to be manifestations of " consciousness "; i.e., " subjective ", hence derivative. Thus the " primacy of sociology over psychology" (to put it crudely) is equated to the primacy of " matter over mind".

I believe this dichotomy to be something carried over from Cartesian dualism, and I very much doubt whether it continues to serve any constructive philosophical purpose. If the materialist view is to be carried to its logical conclusion, then "consciousness " can also be interpreted materialistically, namely as a state of a nervous system, defined by an instantaneous distribution within it of electric potentials, chemical gradients, etc. Thereby the need of the materialist to view all reality as a configuration of matter is satisfied. Note, however, that if this view is strictly adhered to, then there is no logical inconsistency in viewing "consciousness" (in its materialist interpretation, that is) as " primary ", and the "laws governing the transformations of society " as " secondary ". Indeed, such a view would actually be an expression of the ultimate goal of analytic methodology. Recall the derivations of planetary orbits from the infinitesimal elements of motion, of the gross thermodynamic laws from molecular motion, of the properties of compounds from atomic theory, and, more recently, of the properties of atoms from the electronic and nuclear structures - all triumphs of analytic methodology. The mate- 
rialist's dream could well be the derivation of history from the laws of neurophysiology!

The dream, however, is not realistic, at least not now. One reason is the sheer magnitude of the task. Another more important reason is that we have no assurance that our repertoire of concepts is sufficient to undertake the task even if it were manageable. Of the above listed successes of the analytic approach, only the first (celestial mechanics) can be credited to " pure " analysis. The orbits of planets were indeed derived from infinitesimal elements of motion. Note, however, that this was done in an extremely simple context - that of the two-body problem. In higher celestial mechanics it already became necessary to invoke " holistic " (macro-system) concepts, for example, Hamilton's Principle. Here it can still be argued that the analytic approach was not by-passed, since Hamilton's Principle is, after all, derivable from mechanics. However, as has been pointed out, already in thermodynamics principles had to be invoked which had not yet been derived from mechanics; e.g., the heat equivalent of work, the maximization of entropy, etc.

The same is true of other successes of analytic methodology. Chemistry was well under way before Dalton's atomic hypothesis became its foundation, and quite mature long before the gross structure of the atom (not to speak of the structure of the nucleus) was discovered. In all these instances, the repertoire of concepts had to be considerably enlarged (while the investigations of the " higher " contexts was in progress) before the link between the more "fundamental " levels and the higher levels could be established. The concepts of the " fundamental " levels simply did not suffice for the construction of the higher level theories. The "fault " is not in nature, but in us. We simply do not have sufficient memory capacity to operate on all levels with only the fundamental concepts. Think of what an impossible task it would be, for example, to develop all of mathematics using exclusively the concepts of set theory or of symbolic logic, even though a reduction of all mathematical concepts to the latter might be shown to be possible. Whitehead and Russell attempted the task, but they could undertake it only after the mathematical edifice had been contructed in its main outlines.

If it were possible to derive sociology from neurophysiology, then the Marxist tenet (implying the "objectivity" of social processes as against the " subjectivity" of psychological processes) would be refuted by the materialist thesis itself! In the light of this thesis, the psychological processes are just as "objective" (in the sense of being manifestations of material events in the nervous system) as the social processes; and also they are more " fundamental ", being events on a "lower " level of reality.

However, this philosophically conceived " primacy of psychology" does not, at least today, seem to be of much practical methodological consequence. The understanding of social phenomena has become an urgent need ever since the radical transformation of society has accelerated to the point where it is visible during a normal life span. We must therefore 
resort to holistic system approaches and forego, at least for the time being, the ultimate goal of the analytic method. This is a methodological (not a metaphysical) justification for the primacy of sociology over psychology; in Marxist terms, of the "objective" social dynamics over consciousness.

SOCIOLOGY OF KNOWLEDGE

Of the specific consequences of this view I think the most challenging and important is the idea of the sociology of knowledge. In the Marxist formulation, as is well known, the roles assigned in the productive process stratify societies into classes, and the class interest of each stratum shapes its view of the world, in particular, its epistemology. Thus the macrosystem exerts an influence on its constituent parts. In my opinion, it has been an immensely fruitful view when applied to the analysis of political ideologies and of the ethos of Western countries, beginning with the rise of mercantilism through the Industrial Revolution to the growth of socialistcommunist labor movements. I do not know to what extent this view can be extended to other cultures or other eras. I think also that the most impressive manifestations of the class-interest-determined world views are those which reveal themselves in political philosophies. I do not know to what extent class interest reveals itself in other aspects of the world view. Of particular interest are the apparent sources of Western liberalism, rooted in the axiom of natural rights (individual freedom) that has been interpreted by the Marxists as the sublimated expression of the class interest of the bourgeoisie. The capitalist mode of production rests on the commodity market, in which labor is also a commodity. Consequently, contractual obligations must be given precedence over status obligations. Labor, therefore, must be "free "; that is, free to be bought and sold. Mobility of the population must be assured, since new industrial sites spring up near newly discovered or captured sources of raw materials. Moreover, expanding technology requires expanding education and expanding physical science, which, in turn, go hand in hand with freedom of thought and expression. Put these together and you have the 19th century liberal view pressing for the abolition of serfdom (or slavery in the United States), for universal suffrage, civil rights, education of the masses, and a reliance on science (of the 19th century).

The same attitudes, persisting in the 20th century, have frozen into a dogma and have in many instances impeded societies from adapting to changing conditions. The United States offers a dramatic example of this lag. The dominant view of society in the United States has been an atomistic one, rooted in the Arcadian ideal of Jefferson who pictured the future of America as that of a nation of free-holders, each maximally self-sufficient and beholden to no one. As the society became urbanized and commercialized, the "small businessman " supplanted the free- 
holder as the archetype for democracy. This ideal still persists in nostalgic images and inspires the ideological formulations of the political Right.

IDEOLOGICAL CONFLICT IN THE UNITED STATES

Now, what strikes me about the materialist interpretation of the so-called free enterprise ideology is that it is so much more convincing when applied to the early stages of American society than to its later stages. The relation between the needs of the entrepreneur class, operating in an internally expanding economy, and individualistic ethos (especially in its Puritan garb) is quite apparent. The principal character in 19th century America was the entrepreneur, and he could operate " best " only if he was completely unencumbered by any obligations except those involving monetary transactions; only if the drive from which he derived his energy (or his unlimited appetite) was not only tolerated but actually adulated in the prevailing mores.

It is needless to point out that the America of the late 20th century is quite unlike that of the late 19th. The driving, grabbing entrepreneur, tycoon, empire builder is no longer the archetype, certainly not the ideal of social virtue. If Horatio Alger wrote today, who would read him? The Puritan world view was effectively shattered in the Great Depression and replaced by the " 20 th century liberal " view in which the idea of the welfare state (within the framework of "free enterprise ") finds various degrees of assent.

In the climax of the " liberal era ", that is, on the eve of the Vietnam War, the favorite theme of the anti-Marxist liberals in the United States has been that of alleged democratization of capitalism. Indeed, it was possible to deny that the capitalism of the 1960's bore any recognizable resemblance to that of the 1880's. The tycoons vanished from public view. The corporations became de-personalized and appeared to be operating within socially imposed regulations. Beginning with 1933 the United States made significant strides toward catching up with the technologically advanced countries of Europe in social legislation and welfare. Above all, at least the skilled worker population had been preempted into the vast middle class, so that until the outbreak of the campus and ghetto rebellions, it was difficult to refute the argument that ideology was dead in American political life.

It wasn't, of course. It only seemed as if ideology was supplanted by pragmatic problem-solving modes of thought. The reason ideology seems to have " petered out " in the United States in the 1950's was because no counter-ideology challenged the established " mainstream " ideology. (An ideology, like the axiomatic foundation of a deductive system, is visible only against a background of its negation.) 
Nevertheless, as the 1960 's progressed a very different picture emerged. Suddenly a full-fledged ideological struggle flared up, the Establishment having become a target of an onslaught comparable in fury to the onslaught against the ancien régime on the eve of the French Revolution. And here is what appears at first thought to be an embarrassing difficulty for Marxist theory : the ideological clash developed, but not across the traditional seams of class structure.

To be sure, to the extent that one can speak of the emergence of a " revolutionary mass" in the United States, the black ghetto is the closest thing to it. But it is precisely here that the struggle lacks genuine ideological content. The Black Power slogans are desperate outcries against immediate outrages rather than an ideology in the making. To the extent that Black Power leaders attempt to provide an ideological base for a revolutionary movement, they give a faltering, sorry performance, mixing a naively romanticized image of African pre-history with a primitive, debilitating racism, which mirrors the idea of South African apartheid. The Black Power movement is at its best when it makes immediate, concrete demands, and engages people in organized efforts to seize local political control. But these are precisely the non-ideological aspects of the struggle. Ironically, demands of rights and political maneuvers are the established methods of social conflict in American society. So, in this respect, the black people constitute just another pressure group, not a new social class with an emergent class consciousness, imbued with a new ideology. The sociological argument of the end-of-ideology enthusiasts is precisely that social conflict in the United States (and in other technologically advanced countries) is among pressure groups, not social classes. The pressure groups engage in conflicts of interest within a single framework of thought (which to the anti-ideologists appears pragmatic, hence non-ideological) in the same way that commercial firms compete for shares of the market.

The situation is quite different among the strata of American society where alienation from the " mainstream" stems from the role which the United States has assumed in the world. Here an ideology is emerging as a challenge to the traditional "liberal "world view; and in the light of this dialectic opposition the latter now appears to the alienated as a reactionary ideology. The challenge is to the notion that in exercising its power the United States is exercising "leadership".

Ideological opposition to the conduct of the United States on the world scene began at the very start of the Cold War. In the beginning, however, it was rather narrowly confined to the remnant of the Old Left. The Old Left had depended for its ideological nourishment largely on a solidarity with the Soviet Union, which appeared in the Litvinov period 1934-1938 as the only reliable bulwark against the onslaughts of the totalitarian aggressor states. Already then, however, this identification was befuddled by the Stalinist Terror of 1937-1938. It was all but shattered by the Nazi-Soviet pact of 1939 . The pro-Soviet orientation was revived in 1941, only to be dealt another blow by the second explosion of Stalinist 
xenophobia in the late forties. The failure of the Wallace presidential campaign in 1948, and the McCarthy witch-hunt mark the lowest ebb of the Old (pro-Soviet) Left. For this reason, opposition to the Cold War, which was at first practically confined to the remnants of this stratum, was extremely weak in the early 1950's. Opposition began to gather momentum in 1956. The factors contributing to the resurgence were, first, de-Stalinization, then the establishment of the nuclear balance of terror (about 1960), then the overt commitment of the United States to military " containment of communism " by suppressing revolutions. The intensification of the opposition brought on, as might have been expected, a militant support of Cold War policies. I am speaking now not of the conditioned reflex type of support characteristic of the American business community (in which the organized labor leadership must now be included), of the mass media, etc., but of active ideologically rationalized support by the intellectual leadership of the Liberal Establishment. In essence, this support echoes the Administration's pronouncements about America's mission in the " defense of the free world". The ideological basis is provided by identifying " national interests " of the United States with the interest of humanity. The role of the United States is presented by the intellectual apologists of American foreign policy as that of guiding the world along the path of orderly development toward affluence and democracy. To accomplish this task, the United States must (it is maintained) render its power (which is seen as " peace-keeping " power) unassailable. Hence, it is argued, the United States is justified in using its military might whenever and wherever this power is challenged.

PRO JECTION OF THE LIBERAL

A N D MARXIST THESES TO THE WORLD SCALE

It seems to me that this image is the extension to the world arena of the liberal anti-Marxist ideology developed in the West in the past fifty years. The issue between Marxism and Liberalism, it will be recalled, was the question of the role of the class struggle in social change. Marxist extrapolation of the trends initiated by the Industrial Revolution predicted a progressive impoverishment of the working classes, a growth of class consciousness in them, culminating in an organized political struggle, the seizure of political power (i.e., of the state apparatus, including its instruments of coercion), and a re-organization of society in accordance with the interests of the working class, leading to the final abolition of classes. If the history of the United States and of Western Europe is examined in isolation (that is, without reference to the rest of the world), the Marxist thesis appears to have been refuted. The working classes in the technologically advanced countries have not been pauperized; the proletariat has not engulfed the middle class ; on the contrary, the 
middle class, having changed its economic base, has engulfed a large sector of the would-be proletariat. Nor has the " state apparatus " remained essentially an instrument of internal coercion. In the United States, the compliance of the population with the interests of the business community is assured far more effectively and, for the most part, unintentionally by subtle and diffuse means of persuasion. Finally, the welfare state, exemplified by the small democratic countries of Europe, resembles a realization of the aspirations of 19 th century socialists, and the anti-Marxists are quick to point out that this development came about without any visible manifestation of the processes envisaged in Marxist models.

In doing so, the anti-Marxists omit a salient fact of recent history, namely that, on a world scale, the masses are being progressively impoverished; that the gap between the rich and the poor is increasing; that in the world as a whole (in contrast to the technologically advanced countries) a revolutionary consciousness is increasing; that the methods of suppressing revolutionary outbursts in the underdeveloped countries do resemble those of the police of capitalist states in the days when the labor movements in those states were revolutionary.

In other words, on the world scale, the classical Marxist picture of the class struggle is seen rather clearly, even though it is obscured in those portions of the world which Marx had singled out for attention. In certain respects, therefore, we are witnessing a vindication of the Marxist model. There are, however, important discrepancies which must be recognized if the Marxist model is to be brought into conformity with recent historical experience.

First, the Marxist model assigned the revolutionary role to the industrial proletariat. The industrial workers now form an integral part of bourgeois society in the rich Western countries, in the sense of having a stake in preserving important features of these societies. In particular, in the United States the industrial workers, at least by their official political stance, support the goals of the ruling elite. Whatever revolutionary energy stemming from class consciousness exists in the world today seems to be vested in the dispossessed populations of the technologically underdeveloped countries, not in an industrial proletariat of advanced countries, as envisaged by Marx.

Second, if we redraw the " class lines " so that they correspond to a confrontation between the advanced countries (in the role of the owning class protecting its privileges) and the starving masses of the excolonial world, we are faced with the prospect that bears only a superficial resemblance to the social revolution as it was envisaged in the Marxist model. The proletariat which was expected to " seize power " in Marxist eschatology was a highly disciplined, organized social unit. It was destined to carry out a revolution in a society already highly organized, thereby gaining control of already existing institutions. On the other hand, the social revolution envisaged as a world war between the urban and the 
rural worlds (as, for example, in Chinese eschatology) has none of these features. If such a war were to occur (incidentally with the U.S.S.R. on the side of the rich, which is part of the same vision), it is difficult to see anything emerging from the resulting holocaust that remotely resembles an organized socialist society. The Maoist vision, while it captures certain important aspects of the impending struggle, is still too swathed in romantic fog to be seriously considered as a variant of, or a successor to, the classical Marxist model of social revolution.

A struggle is indeed shaping up on the world scale between those who represent entrenched power and those who represent the aspirations of humanity; but it seems to me that the lines of that struggle can no longer be drawn along the same chasm that separated the economic classes of Europe from each other in the nineteenth century.

If we turn our attention once again to the ideological strife now raging in the United States, we can only conclude that its momentum cannot be provided by a class struggle in the traditional sense. As I have said, the bulk of organized labor and certainly most of its bureaucratized leadership (it has no other) supports both the goals and the methods of United States imperialism. Articulate and sustained opposition to the goals of the American power elite originated in sectors of the academic and the religious communities, and, to the extent that it has spread, it has penetrated all social strata without apparent relevance to discernible economic interests.

On the other hand, it does seem that the classical theory of imperialist expansion (propelled by the dynamics of monopoly capitalism) still provides a rather convincing explanation of the role assumed by the United States in world affairs. In other words, Marxist doctrine of economic dynamics still seems to be an adequate theoretical basis of large scale global events (to the exent that these are instigated by pressures acting on the power elite); but Marxist sociology of knowledge, in its original formulation, does not seem to account for the ideological divisions prevailing in our era. In its classical version, it fails to explain the ideological rift between Chinese and Soviet elites. If, instead of the classical doctrine, the Maoist version is adopted, this places the Soviet Union and its allies in the "capitalist camp ", in which case nothing remains of "the world industrial proletariat " as a bearer of a socialist revolution.

Specifically, Marxist sociology of knowledge is inadequate to account for the ideological struggle within the United States. To be sure, in the Maoist version this struggle may be of no consequence (as the struggle between liberals and conservatives was viewed by the communists in the 1920's and 1930's). But it must not be dismissed on that account. While the prospects of restraining American imperialism from inside the United States are not bright, the impact of the protest movement should not be discounted. It may well contribute to the creation of a climate of world opinion which will make it increasingly difficult for the United States to carry out its self-assumed role as the Defender of the Faith. 
Finally, the threat of the nuclear holocaust is a factor in our time that has not the remotest analogue in the 19th century. The ruling classes of the 19th century prepared, as a matter of routine, to wage wars against each other in the pursuit of their " national " and imperialist interests. Today the only great power waging or preparing to wage wars of aggression is the United States; and it is taken for granted by its military establishment that these wars will be normally "limited wars ", with the objective of suppressing revolutions, and only in extremis a total war, envisaged as a confrontation with China or the Soviet Union or both. In the rest of the capitalist world, war has ceased to be viewed as an instrument of national aggrandizement, while in most communist countries war is envisaged only as a defense against the onslaught of the United States. These radical changes in the conception of war have inevitably introduced into ideology new factors difficult to relate to " class interests ". While in the days of mass armies the burdens of war were largel; borne by the masses and escaped by the elites, the nuclear bomb does not recognize class distinctions. It is an anomaly, but not an accident, that there is more opposition to American military adventures in the business community than in the ranks of organized labor.

Marxist philosophy laid the foundations of a sociology of knowledge. But this version of the sociology of knowledge, which provided an intriguing and provocative explanation of the clashing ideologies of the past centuries, cannot be expected to give us additional insights into the events of our era. We have witnessed social upheavals which only a pedant would insist on explaining in terms of the broad outlines of social dynamics bequeathed by Marx.

In particular, we need to know a great deal more about " social biology ". Human aggregates share certain characteristics with organisms. This is hardly surprising. Among lower forms of life the boundary between " individual " and "aggregate" is often not clear. A colony of social insects, for example, is an organism in many of its aspects, related to its constituent individuals as the latter are related to the cells that compose them. Cybernetics has revealed a great deal about the behavior of complex systems as they are determined by the interactions of their parts regardless of the specific nature of these systems; whether, for example, they are mechanical, chemical, or electrical; whether living or dead. Possibly a great deal can be revealed about social systems by the use of the general methods developed in cybernetics, which, incidentally, are already shown to be relevant to economics. They may also be relevant to macro-social psychology, which is essentially the content of the sociology of knowledge. However, if we are to take a cue from cybernetics, we must abandon the hope of discovering "laws " that can be stated in ordinary language in which it has been possible to enunciate only the most elementary of the so-called "laws of nature ". The behavior of complex organized systems is governed not by simply stated "laws " but by intricate networks of inter-relations which constitute the organization of the systems. For 
this reason the so-called " laws of development of societies " stated verbally as general principles (analogous to the conservation laws of physics or the principle of natural selection in biology) are not likely to yield more than they have already yielded.

We need to know a great deal more about how " reality " is transformed in being perceived by man. It is not enough to resort to a metaphor, as Lenin did in his "doctrine of reflection". This model served the purpose of reiterating the " primacy of matter over mind " (by negating the autonomy of " mind "), but it tells us nothing of how reality is reflected in consciousness. Marx's sociology of knowledge says a great deal about how perceptions of reality are refracted (not reflected) by class interests, but to insist that this is a sufficient " explanation " of the differences among perceptions and commitments is to shut off further inquiry.

We know that between our consciousness and reality there is interposed a screen of language. For the most part we do not observe reality directly but only via the images projected on that screen. These images are formed by verbal categories which constitute the content of most of our thoughts. The verbal categories enter our lives at an age when we are not in a position to examine critically the correspondence between them and non-verbal experience. The verbal categories organize our experiences into concepts which, in turn, serve as a framework into which further experiences are fitted. Experiences which do not fit the established frameworks are not likely to be registered at all. The propensity to identify verbal categories with reality makes us vulnerable to all sorts of persuasive manipulation, including demagogy. Indeed, the insulation from direct experience effected by the verbal screen seems to be a plausible explanation of how it comes about that masses can be induced to act against their class interests. On the other hand, the power of symbols suggests that at times cohesive groups are motivated by pressures difficult or impossible to relate to the roles the groups play in the productive process (e.g., nationalism, religious zeal, symbolic social status, etc.).

Marxism has paid little attention to this dimension of social reality. Taking note of this omission does not detract from Marx's achievement in having laid the foundations of an analysis of the sociology of knowledge based on the interaction of demonstrable class interests, and ought not to be avoided because of (real or imagined) " threats" to the Marxist world view.

\section{PHILOSOPHY OF HISTORY}

Of all the contributions of Marxism to our intellectual heritage, Marxist philosophy of history is, perhaps, the furthest removed from currently prevailing Western views. It is frankly an eschatological doctrine, a view of history as the unfolding of a scheme and the attainment of a goal. 
Marx's intellectual debt to Hegel is common knowledge. Indeed, Marx's achievement is seen by the Marxists as that of having turned Hegel right side up; i.e., having put Hegel's evolutionary philosophy of history on a solid materialist base.

In our day, the optimistic prognoses of Marxist eschatology are not easy to accept, especially in the West. For one thing, the conception of evolution as " progress" has become ambivalent, not to say suspect. All progress must be defined in terms of goals, that is, in teleological terms. But the teleological point of view has suffered many serious reverses. The realization of a Divine Purpose is no longer taken seriously except by believers, who no longer enjoy a hegemony in philosophy. To be sure, Marxism has expunged Divine Purpose from its theory of social evolution by substituting " laws of historical development " for Hegel's realization of the Idea. However, these " laws of historical development " amount at best to no more than an extrapolation of selected historical trends combined with an aspiration for a just social order. The "inevitability " of the just social order is argued on the premise of the cooperative nature of modern production. Implicit in the argument, however, is the assumption that an organized society will survive as a matrix of human existence. There is no way of justifying this assumption; indeed, no way of justifying the assumption that man as a species can long survive.

The ephemeral nature of all hitherto existing social orders based on the exploitation of man by man is argued by the Marxists on the grounds that every exploitative social order brings about a class struggle and so carries within it the seeds of its own destruction. The end of this process is foreseen in the establishment of a social order in which the fruits of labor of some are not appropriated by others. The implication is that " appropriation of the fruits of labor " is the only important form of exploitation. This may well have been the case when domination was motivated and maintained by the opportunities it provided for avoiding toil. But must this be the case when the necessity for toil has been removed from human life? Do we not find ample evidence of a vast variety of contexts in which domination occurs, seemingly unrelated to appropriation of the fruits of others' labor? Do men struggle for power only to make others toil for them? Was the usurpation of total power by Stalin motivated by Stalin's (or for that matter his bureaucracy's) desire to avoid toil? As a matter of fact, the modern dictator is typically an indefatigable, dedicated toiler, often a severe ascetic. In the past, Marxists went to great lengths to avoid even posing such questions, let along grappling with them, probably because the idea that debilitating and disruptive conflicts may develop even in the " classless society " was seen by them as damaging theory. In particular, orthodox Marxists were quick to dismiss summarily any approach to the study of man that puts at the point of departure the psychological make-up of man derived from his biological heritage. For example, it has always been difficult to induce an orthodox Marxist 
to close his eyes for a moment on man as a producer and consumer of commodities in order to see him as a complex of unconscious drives; that is, as an animal organism, as he is pictured, say in the Freudian model. The Marxists nurture an impregnable faith in man's ability to shake himself loose from the blind, propelling forces of history and to take his fate into his own hands.

Although the optimistic historicism of Marxist philosophy is challengeable on the grounds of a disturbing accumulation of evidence concerning the possibly inherent inadequacies of man as a species, one aspect of this philosophy endows it with a certain credibility. Predictions made in the context of human affairs are different from predictions made about the non-human world, in that such predictions are frequently self-realizing (or self-refuting). Significantly, the self-realizing aspect of Marxist philosophy of history is an explicitly recognized part of that philosophy; so that, in it, the predictive and the prescriptive modes of discourse are not separable. (The obverse side of this aspect is expressed in Engels' aphorism: "Freedom is the recognition of necessity ".) To put it bluntly, what man is and what he will become is not entirely determined by a set of " objective conditions" but also in part by what man believes he is or will become. Curiously, this argument was used by Karl Popper as a refutation of what he conceived to be Marxist historicism, whereas the merging of prediction and choice (of freedom and necessity) is the very essence of Marxist historicism. Thus the Marxist prediction of the growing class consciousness of the European working class became for a time a determining condition of the emergence of that consciousness.

This self-predictive component of man's evaluation of himself, in particular of historical prognosis, must be kept constantly in mind. In making historical prognoses we are not merely estimating the course of events, and consequently are assuming responsibility for them. Therefore the ideal of scientific objectivity cannot be strictly applied to the context of historical prognosis, unless one is impervious to one's responsibility as a human being. Unlike meteorological predictions, historical predictions involve an ethical choice. The recognition of this principle is, in my opinion, the most important intellectual legacy of Marxist philosophy of history.

To summarize, Marxism was the first systematic attempt to apply insights obtained from an analysis of social dynamics (by means of tools then available) to both the prediction and the direction of the course of history. The distinction between the two is not sharp in Marxist philosophy, which declares that the understanding of the world is conferred on man by efforts to change the world. C. Wright Mills put it picturesquely when he said that the surest way to be convinced of the "reality " of the power elite is by trying to buck it. Conversely, understanding the forces which propel the evolution of society confers upon man the power to direct these forces. It would be a grievous mistake to view the Marxist synthesis as the last as well as the first one of its kind. If a philosophy of 
history is to be a serviceable tool (a "weapon ", as the Marxists are fond of saying) for carrying out the aspirations of humanity, it must not be allowed to freeze into a dogma. All the protestations of non-commitment to dogma notwithstanding, the record of the politically practising Marxists (i.e., those in the position of leadership in communist states) has not been good in this respect. A certain ossification of doctrine is understandable and even excusable in men who must make risky decisions and rationalize them on "scientific " grounds. But it is most unfortunate if ossification is permitted on the intellectual level; that is, in the minds of thinkers not obliged to make quick and far-reaching political decisions. Those whose business it is to develop a science of man-in-society should not only be free but also should feel free to construct a great variety of models and theories, to challenge or modify existing ones, to offer alternative interpretations; in short, to do everything that scientists do to scientific theories, and philosophers do to philosophy. It may well be that in the light of new insights and experiences little will be left that resembles the original formulations of Marxism. But this will by no means imply that Marxism will have been discarded or corrupted or diluted. We do not negate our childhood by becoming men; nor do we debase the insights of our teachers by outgrowing them.

Anatol Rapoport is Professor of Mathematical Blology at the University of Michigan, and editor of the yearbook General systems. Recent publications : Fights, games and debates (1960); Strategy and conscience (1964); Two-person game theory Essential ideas (1966). 